\title{
$\mathrm{M}|\mathrm{R}| \mathrm{S}$ Internet Journal Nitride Semiconductor Research
}

\section{Aluminum Nitride-Silicon Carbide Alloy Crystals Grown on SiC Substrates by Sublimation}

\author{
Z. Gu${ }^{1}$, L. Du ${ }^{1}$, J.H. Edgar ${ }^{1}$, E.A. Payzant ${ }^{2}$, L. Walker ${ }^{2}$, R. Liu ${ }^{3}$ and M.H. Engelhard ${ }^{4}$ \\ ${ }^{1}$ Department of Chemical Engineering, Kansas State University, \\ ${ }^{2}$ Oak Ridge National Laboratory, High Temperature Materials Laboratory, \\ ${ }^{3}$ Department of Physics and Astronomy, Arizona State University, \\ ${ }^{4}$ Environmental Molecular Sciences Laboratory, Pacific Northwest National Laboratory,
}

(Received Monday, November 28, 2005; accepted Monday, December 19, 2005)

\begin{abstract}
AlN-SiC alloy crystals, with a thickness greater than $500 \mu \mathrm{m}$, were grown on $4 \mathrm{H}-$ and $6 \mathrm{H}-\mathrm{SiC}$ substrates from a mixture of $\mathrm{AlN}$ and $\mathrm{SiC}$ powders by the sublimation-recondensation method at $1860-1990{ }^{\circ} \mathrm{C}$. On-axis $\mathrm{SiC}$ substrates produced a rough surface covered with hexagonal grains, while $6 \mathrm{H}$ - and $4 \mathrm{H}$ - off-axis $\mathrm{SiC}$ substrates with different miscut angles $\left(8^{\circ}\right.$ or $\left.3.68^{\circ}\right)$ formed a relatively smooth surface with terraces and steps. The substrate misorientation ensured that the AlN$\mathrm{SiC}$ alloy crystals grew two dimensionally as identified by scanning electron microscopy (SEM). Xray diffraction (XRD) and transmission electron microscopy (TEM) confirmed that the AlN-SiC alloys had the wurtzite structure. Electron probe microanalysis (EPMA) and x-ray photoelectron spectroscopy (XPS) demonstrated that the resultant alloy crystals had non-stoichiometric ratios of $\mathrm{Al}: \mathrm{N}$ and $\mathrm{Si}: \mathrm{C}$ and a uniform composition throughout the alloy crystal from the interface to the surface. The composition ratio of $\mathrm{Al}: \mathrm{Si}$ of the alloy crystals changed with the growth temperature, and differed from the original source composition, which was consistent with the results predicted by thermodynamic calculation of the solid-vapor distribution of each element. XPS detected the bonding between $\mathrm{Si}-\mathrm{C}, \mathrm{Si}-\mathrm{N}, \mathrm{Si}-\mathrm{O}$ for the $\mathrm{Si} 2 p$ spectra. The dislocation density decreased with the growth, which was lower than $10^{6} \mathrm{~cm}^{-2}$ at the alloy surface, more than two orders of magnitude lower compared to regions close to the crystal/substrate interface, as determined by TEM.
\end{abstract}

\section{Introduction}

Aluminum nitride-silicon carbide alloys can be prepared with a wide range of physical and electronic properties that are superior to the pure binary components. This is an excellent system for bandgap engineering, as its band gap changes from $6.2 \mathrm{eV}$ (for AlN) down to $2.9 \mathrm{eV}$ (for $6 \mathrm{H}-\mathrm{SiC}$ ), and potentially $2.3 \mathrm{eV}$ if the cubic structure $3 \mathrm{C}-\mathrm{SiC}$ can be stabilized. The band transition changes from indirect for $\mathrm{SiC}$-rich to direct for AlN-rich alloys $(>70 \%)$. Both $n$ and $p$ type conductivities have been reported. AlN-SiC alloys retain the best properties of the pure binary compounds: high electron break down field, high saturated electron drift velocity, and high thermal conductivity [1] [2] [3] [4] [5] [6] [7] [8].

Much research has already been carried out on the preparation and characterization of AlN-SiC alloy crystals. Both thin films and bulk crystals of AlN-SiC alloys have been prepared over the entire compositional range.
Solid solutions of epitaxial $(\mathrm{SiC})_{1-x}(\mathrm{AlN})_{x}$ thin films with a full range of $x$ (from 0 to 1 ) were successfully grown on $6 \mathrm{H}-\mathrm{SiC}$ substrate by the sublimation method [9]. The source materials were polycrystalline SiC-AlN solid solution plates with different AlN concentrations. The resultant polytypic structure was dependent on the AlN concentration: epitaxial $(\mathrm{AlN})_{x}(\mathrm{SiC})_{1-x}$ films had the $2 \mathrm{H}$ polytype (i.e. the wurtzite structure) in the range of $x=0.2$, while different polytypic structures $(3 \mathrm{C}, 4 \mathrm{H}$, $6 \mathrm{H}, 2 \mathrm{H})$ were possible when $x<0.2$. Moreover, the composition strongly affected the morphology and structural quality of $(\mathrm{AlN})_{x}(\mathrm{SiC})_{1-x}$ solid solutions. The surface morphology and quality deteriorated with the AlN concentration, which was probably due to the increasing mismatch between the film and substrate [9]. Previously we reported on the sublimation growth of AlN$\mathrm{SiC}$ alloy crystals on off-axis $\mathrm{Si}$-face $6 \mathrm{H}-\mathrm{SiC}$ (0001) substrates from a mixture of $\mathrm{AlN}$ and $\mathrm{SiC}$ powders [10]. 
A homogeneous AlN-SiC alloy grew two dimensionally with a wurtzite structure and high quality.

In addition to sublimation, other methods have successfully grown AlN-SiC alloy crystals on $6 \mathrm{H}-\mathrm{SiC}$ (0001) substrates. Dmitriev et al. [11] produced alloys with AlN concentration up to $10 \mathrm{~mol} \%$ by liquid phase epitaxy (LPE). Jenkins et al. [12] achieved solid solutions of $(\mathrm{AlN})_{x}(\mathrm{SiC})_{1-x}$ over the composition range from $x=0.1$ to 0.9 by metalorganic chemical vapor deposition (MOCVD). A new approach, sequential supply epitaxy (SSE), was developed by Avramescu et al. [13] to improve the quality of AlN-SiC epilayers. Alternating the supply of precursors in a MOCVD reactor greatly reduced the quality-limiting gas-phase reaction and promoted a 2D-like growth at relatively low temperatures $\left(1200-1300{ }^{\circ} \mathrm{C}\right)$. Most recently gas-source molecular beam epitaxy (GSMBE) was employed by Roucka et al. [14] to grow SiCAIN thin films of high hardness on $\mathrm{Si}$ (111) substrates at low temperatures $\left(550-750{ }^{\circ} \mathrm{C}\right)$. An average hardness of $25 \mathrm{GPa}$ was achieved for the SiCAlN films, using fused silica with the hardness value of $9 \mathrm{GPa}$ as a standard. Rutherford backscattering spectrometry (RBS), Fourier transform infrared spectroscopy (FTIR), cross-sectional transmission electron microscopy (XTEM), and electron energy-loss spectroscopy (EELS) measurements confirmed a $2 \mathrm{H}$ wurtzite crystal structure with a near-stoichiometric composition and lattice parameters close to those of $2 \mathrm{H}-\mathrm{SiC}$ and hexagonal AlN. A novel method - ion beam synthesis - was performed on (0001)-oriented, $n$-type $6 \mathrm{H}$-SiC wafers by co-implanting $\mathrm{N}^{+}$and $\mathrm{Al}^{+}$ions to synthesize $(\mathrm{SiC})_{1-}$ ${ }_{x}(\mathrm{AlN})_{x}$ layers. High substrate temperature $\left(=600{ }^{\circ} \mathrm{C}\right)$ and the sequence of implantation of $\mathrm{Al}$ followed by $\mathrm{N}$ were favorable to the crystal growth [15].

In this paper, we report on the composition and structural properties of AlN-SiC alloy crystals grown by sublimation on $\mathrm{SiC}$ substrates. Growth of AlN-SiC alloy crystals on $8^{\circ}$ off axis (0001) $6 \mathrm{H}-\mathrm{SiC}$ substrates was studied in detail. The original composition of the source material was varied to examine its effect on the AlN-SiC alloy crystals grown on $8^{\circ}$ off-axis $4 \mathrm{H}-\mathrm{SiC}$ substrate. This was complemented by thermodynamic calculation to predict the $\mathrm{Al}$ to $\mathrm{Si}$ ratio in the gas phase to see its relevance to the composition in the solid. The effect of the polytypes and intentional misorientation of the $\mathrm{SiC}$ substrates on the AlN-SiC alloy crystals was investigated. Different techniques were performed to characterize the AlN-SiC alloy crystals: optical microscopy and scanning electron microscopy (SEM) for the surface morphology; x-ray diffraction (XRD) for identifying the crystal and lattice constants; transmission electron microscopy (TEM) for the defect identification and high magnification information on the interface and surface properties; electron probe microanalysis (EPMA) for the composition analysis; and x-ray photoelectron spectroscopy (XPS) for both the composition and bonding information.

\section{Experimental}

\subsection{Crystal growth of AIN-SiC alloy on SiC sub- strate}

The sublimation growth of AlN-SiC alloy crystals was conducted in a resistively-heated graphite furnace. The growth chamber consists of a graphite retort surrounding a crucible to contain the highly reactive source vapors. The graphite heating element was designed to provide an axial temperature gradient of $5-10{ }^{\circ} \mathrm{C} / \mathrm{cm}$ between the source material and crystal growth region, which was the driving force for the sublimation growth. The distance between the source and the substrate was kept constant at $\sim 1 \mathrm{~cm}$. Ultra high purity nitrogen continuously flowed through the system at a constant pressure of $\sim 810$ Torr. The source AlN-SiC mixture powder was obtained by mixing ultra high purity AlN powder with $\mathrm{SiC}$ powder.

The effects of three process parameters on the properties of the $\mathrm{AlN}-\mathrm{SiC}$ layers on $\mathrm{SiC}$ substrates were investigated: the substrate polytype and misorientation; temperature; and the composition of the original source. AlN-SiC alloy crystals were grown on different polytypes of $\mathrm{SiC}$ substrates at $1850{ }^{\circ} \mathrm{C}$ for $24 \mathrm{~h}$. The seed crystals were Si-face (0001) $6 \mathrm{H}-\mathrm{SiC}$ substrates intentionally misoriented $8^{\circ}\left( \pm 0.5^{\circ}\right)$ off axis toward $(1 \overline{1} 00)$, $6 \mathrm{H}-\mathrm{SiC}$ misoriented $3.68^{\circ}$ off axis toward $(11 \overline{2} 0)$, on axis $\left( \pm 0.5^{\circ}\right) 6 \mathrm{H}-\mathrm{SiC}$, and $4 \mathrm{H}-\mathrm{SiC}$ misoriented $8^{\circ}( \pm$ $\left.0.5^{\circ}\right)$ off axis toward $(11 \overline{2} 0)$. The sublimation growth of AlN-SiC alloy crystals on $8^{\circ}$ off axis $6 \mathrm{H}-\mathrm{SiC}$ was studied in detail over the temperature range from $1860^{\circ} \mathrm{C}$ to $1990{ }^{\circ} \mathrm{C}$. The mole ratio of $\mathrm{Al}: \mathrm{Si}$ in the source material was 3:1. To study the effect of the source composition on the AlN-SiC alloy crystals, the composition ratio of $\mathrm{Al}: \mathrm{Si}$ in the source material was varied at 2:1, 3:1 and $5: 1$. The alloy crystals were grown on $8^{\circ}$ off-axis $4 \mathrm{H}$ $\mathrm{SiC}$ substrate. Growth at three different temperatures within $1800-2000{ }^{\circ} \mathrm{C}$ was performed under the same composition ratio.

\subsection{Characterization}

The surface morphology was examined by optical microscopy (low magnification) and scanning electron microscopy (SEM, high magnification). The lattice constants and crystal identification were measured by x-ray diffraction (XRD) with $\mathrm{Cu}-\mathrm{K} \alpha$ radiation, using a PANalytical X'Pert PRO MPD diffractometer with an incident-beam parabolic mirror, 0.04 rad incident and diffracted beam Soller slits, and an X'Celerator realtime multiple-strip detector. A JEOL 4000EX transmission electron microscope (TEM) with a point resolution 
of $1.7 \AA$ was used to examine the alloy crystals, the crystal/substrate interface properties, and defects. EDX for the composition analysis was realized in a Philip CM200 TEM operated at $200 \mathrm{kV}$. All TEM specimens were prepared by mechanical polishing followed by argon ion milling.

In the previous work [10], scanning Auger microprobe (SAM) was executed to measure the surface elemental composition, and the depth profile of each component. However, the AlN-SiC alloy crystals have a serious charging problem in SAM. In addition, our experience indicates that SAM overestimates the oxygen concentration. Oxygen in the UHV system is adsorbed on the sample surface, leading to a higher concentration of oxygen on the surface than in the bulk. Therefore electron probe microanalysis (EPMA) was performed instead using a focused beam of high energy electrons $(10 \mathrm{keV})$ for elemental analysis. EPMA is less surface sensitive than XPS or AES, and provides more accurate measurement on the bulk sample composition. Before measurements, samples were coated with carbon for conductivity, therefore the carbon concentration was determined by difference. The silicon x-ray had sufficient energy to penetrate the carbon film without absorption. A near 1:1 ratio of $\mathrm{Si}: \mathrm{C}$ was detected in the $\mathrm{SiC}$ substrate, suggesting the accuracy of the EPMA analysis.

The composition and bonding information were obtained ex situ by x-ray photoelectron spectroscopy (XPS) on a PHI quantum $2000 \mathrm{x}$-ray photoelectron spectrometer using a focused monochromatic aluminum $\mathrm{K}$ X-ray beam. Ar ions were employed to sputter the adsorbents off the sample surface. In XPS, the relative concentration of different elements is determined by calculating the peak intensity, using elemental sensitivity factor, spectrometer transmission function, and correction for emission angle. However, XPS is only sensitive to 5-10 monolayers of the surface, therefore the bulk composition measured by XPS may differ from that by other surface sensitive techniques.

\subsection{Thermodynamic calculation}

A thermodynamic calculation was performed to predict the distribution of each element between the source material and the gas phase. Since the alloy crystals are formed from the vapor phase, this provides a theoretical means for estimating changes in the crystal composition with temperature.

The sublimation growth of AlN occurs by the reaction

$$
A i N(s) \Leftrightarrow A l(g)+\frac{1}{2} N_{2}(g)
$$

while in the sublimation growth of $\mathrm{SiC}$ the following reactions can occur:

$$
\begin{gathered}
\operatorname{si}((s) \Leftrightarrow S i(g)+C(s), \\
\operatorname{siC}(s) \Leftrightarrow \frac{1}{2} \operatorname{si} C(g)+\frac{1}{2} C(s), \\
\operatorname{siC}(s) \Leftrightarrow \frac{1}{2} \operatorname{siC}(g)+\frac{1}{2} \operatorname{si}(g), \\
\operatorname{si}(s) \Leftrightarrow \operatorname{si} Q(g) .
\end{gathered}
$$

Reaction (3) is the most important for SiC sublimation, as confirmed by the calculation of Gibbs free energy of reaction for each reaction using the Gibbs free energy of formation from JANAF thermochemical tables. $\mathrm{Al}, \mathrm{N}_{2}, \mathrm{Si}, \mathrm{SiC}, \mathrm{Si}_{2} \mathrm{C}, \mathrm{SiC}_{2}$, and possibly $\mathrm{SiN}$ and $\mathrm{Si}_{2} \mathrm{~N}$ are present in the gas phase, while $\mathrm{SiC}, \mathrm{AlN}, \mathrm{C}$, possibly $\mathrm{Si}_{3} \mathrm{~N}_{4}$ may be present in the solid phase. If assuming that the vapor phase over $\mathrm{AlN}$ and $\mathrm{SiC}$ consists of $\mathrm{Al}(\mathrm{g}), \mathrm{Si}(\mathrm{g}), \mathrm{SiC}(\mathrm{g}), \mathrm{Si}_{2} \mathrm{C}(\mathrm{g}), \mathrm{SiC}_{2}(\mathrm{~g}), \mathrm{N}_{2}(\mathrm{~g})$, $\mathrm{SiN}(\mathrm{g})$ and $\mathrm{Si}_{2} \mathrm{~N}(\mathrm{~g})$, and no AlN molecule, and the $\mathrm{N}_{2}$ pressure of 810 torr, the mole fraction of each species can be calculated from the JANAF data. The original mole ratio of AlN to $\mathrm{SiC}$ in the source material was changed from 2:1 to 3:1 and 5:1.

\section{Results}

The thermodynamic calculation confirmed that $\mathrm{Si}, \mathrm{Si}_{2} \mathrm{C}$, $\mathrm{Si}_{2} \mathrm{~N}$ and $\mathrm{SiC}_{2}$ are the main Si-containing species in the gas phase, and the importance of $\mathrm{Si}_{2} \mathrm{C}, \mathrm{SiC}$ and $\mathrm{SiC}_{2}$ increased dramatically (one order of magnitude for $\mathrm{Si}_{2} \mathrm{C}, 2$ orders of magnitude for $\mathrm{SiC}$, and 2-3 orders of magnitude for $\mathrm{SiC}_{2}$ ) with temperature. Figure 1 displays the predicted change of mole ratio of $\mathrm{Al}$ (in $\mathrm{AlN}$ ) to $\mathrm{Si}$ (in $\mathrm{Si}, \mathrm{Si}_{2} \mathrm{C}, \mathrm{Si}_{2} \mathrm{~N}, \mathrm{SiC}_{2}, \mathrm{SiC}$, and $\mathrm{SiN}$ ) in the gas phase with temperature from $1800{ }^{\circ} \mathrm{C}$ to $2000{ }^{\circ} \mathrm{C}$. It is evident that the mole ratio of $\mathrm{Al}: \mathrm{Si}$ increases with temperature. After reaching a maximum (at $\sim 1910-1920{ }^{\circ} \mathrm{C}$ ), it decreases gradually. The mole ratio of $\mathrm{Al}$ to $\mathrm{Si}$ in the gas phase was different from the original composition ratio of Al:Si in the source material; the gas phase contained a higher Al:Si ratio under most conditions.

Figure 2 shows optical micrographs of an AlN-SiC alloy crystal grown on $8^{\circ}$ off-axis $6 \mathrm{H}-\mathrm{SiC}$ substrate at $1860{ }^{\circ} \mathrm{C}$ for $24 \mathrm{~h}$. The resultant AlN-SiC alloy crystal was colorless and transparent. The film was cracked, 
probably due to the large stress introduced during the cooling process from sublimation temperature to room temperature, which was caused by the thermal expansion mismatch between the SiC substrate and the AlN$\mathrm{SiC}$ alloys. EPMA measurements confirmed that all four constituents, $\mathrm{Si}, \mathrm{Al}, \mathrm{C}$, and $\mathrm{N}$, were present in every region investigated, without any indication of phase separation of $\mathrm{SiC}$ and $\mathrm{AlN}$ or any segregation of individual elements.

Figure 3 displays a SEM image of an AlN-SiC alloy crystal grown on $8^{\circ}$ off-axis $6 \mathrm{H}-\mathrm{SiC}$ substrate at 1860 ${ }^{\circ} \mathrm{C}$ for $20 \mathrm{~h}$. The AlN-SiC alloy was initially deposited in an island growth mode which was evident from the hexagonal pyramids with flat tops. The hexagonal grains then merged together to form a continuous layer.

AlN-SiC alloy crystals grown on off-axis $\mathrm{SiC}$ substrates were basically similar in morphology under optical microscope (as in Figure 2), independent of the different polytypes $(6 \mathrm{H}$ or $4 \mathrm{H})$ and miscut angles $\left(8^{\circ}\right.$ or $3.68^{\circ}$ ). They only differed slightly in the width of terraces and heights of steps. The growth developed layer by layer, with individual hexagonal grains around the sample edges. The steps originally present at the miscut $\mathrm{SiC}$ substrates provided the initial nucleation sites, leading to a three-dimensional nucleation of islands, followed by a two-dimensional layer-by-layer growth due to the island coalescence. In contrast, AlN-SiC alloy crystals formed on on-axis $6 \mathrm{H}-\mathrm{SiC}$ substrate were rough with individual hexagonal islands all over the surface (demonstrated in Figure 4). Therefore, growth on onaxis $\mathrm{SiC}$ substrate was not further investigated.

The lattice constants for one AlN-SiC alloy were accurately measured by XRD. The alloy crystal grown on $8^{\circ}$ off-axis $6 \mathrm{H}-\mathrm{SiC}$ substrate at $1985{ }^{\circ} \mathrm{C}$ for $24 \mathrm{~h}$ (with the original mole composition $\mathrm{Al}: \mathrm{Si}$ as 3:1) was ground to powder so as to obtain the complete XRD spectra. Figure 5 shows the XRD spectra of the ternary AlN-SiC alloy crystal and a binary AlN crystal. The diffraction peak of the AlN-SiC alloy crystal was shifted toward AlN, since AlN was the main component. The XRD patterns confirm that as expected, the $\mathrm{SiC}$ from the substrate was the $6 \mathrm{H}$ polytype. The lattice constants $a$ and $c$ measured for $6 \mathrm{H}-\mathrm{SiC}$ were 3.083(9) $\AA$, and 15.04(2) $\AA$, which were somewhat altered from the values of $a$ and $c$ for a ground $6 \mathrm{H}-\mathrm{SiC}$ substrate without AlN-SiC alloy layer, measured on the same instrument as 3.0818(7) $\AA$ and 15.111(4) A. The AlN-SiC alloy had the wurtzite crystal structure. The lattice constants $a$ and $c$ calculated for the grown AlN-SiC alloy crystal were 3.098(7) $\AA$ and 4.996(9) $\AA$, respectively. The appearance of $\mathrm{SiO}_{2}$ peaks was probably artifacts introduced by the grinding process.

Figure 6 shows the XPS spectra for the AlN-SiC alloy crystal grown on $8^{\circ}$ off-axis $6 \mathrm{H}-\mathrm{SiC}$ substrate at
$1865{ }^{\circ} \mathrm{C}$ for $24 \mathrm{~h}$. The measurement indicated the presence of $\mathrm{Al}, \mathrm{N}, \mathrm{Si}, \mathrm{C}$ and $\mathrm{O}$ elements on the surface. $\mathrm{Al}$ $2 p, \mathrm{~N} 1 s$ peaks of the alloy crystal were compared with those of a pure AlN substrate, and Si $2 p, \mathrm{C} 1 s$ peaks were compared with those of pure $\mathrm{SiC}$ substrate. Both Al $2 p$ and $\mathrm{N} 1 s$ peaks shifted to a slightly higher binding energy in the AlN-SiC alloy crystal in comparison to those in pure AlN substrate. However, C $1 s$ peak shifted to a lower binding energy in the alloy crystal, whereas $\mathrm{Si}$ $2 p$ peak shifted to a much higher binding energy than that in pure $\mathrm{SiC}$ substrate. A higher binding energy was generally associated with a higher positive oxidation state. The shift of Si $2 p, \mathrm{C} 1 s, \mathrm{Al} 2 p$, and $\mathrm{N} 1 s$ peaks as compared with bulk $\mathrm{SiC}$ and AlN confirmed no phase segregation of AlN and $\mathrm{SiC}$, and the formation of AlN$\mathrm{SiC}$ alloy crystals.

Figure 7 shows the Si $2 p$ XPS spectra for the AlN$\mathrm{SiC}$ alloy crystal grown on $8^{\circ}$ off-axis $6 \mathrm{H}-\mathrm{SiC}$ substrate at $1850{ }^{\circ} \mathrm{C}$ for $24 \mathrm{~h}$. The $\mathrm{Si} 2 p$ spectrum was decomposed into four components at 99.07, 100.48, 101.25, and $102.13 \mathrm{eV}$. The employed decomposition parameters were as follows: the full width at half maximum (FWHM) was $1.34 \mathrm{eV}$, and the broadening function, $70 \%$ Gaussian. The $100.48 \mathrm{eV}$ peak can be ascribed to $\mathrm{Si}-\mathrm{C}$, the $101.25 \mathrm{eV}$ peak to $\mathrm{Si}-\mathrm{N}$, and the $102.13 \mathrm{eV}$ to Si-O [16]. The peak fitting results are listed in Table 1. In the AlN-SiC alloy crystal, $\mathrm{Si}$ was not only bonded to $\mathrm{C}$, but also to $\mathrm{N}$ to a large extent. This provides further confirmation that AlN-SiC crystal was actually an alloy without phase separation of $\mathrm{SiC}$ and AlN. However, it is difficult to apply the same procedure to the $\mathrm{Al} 2 p, \mathrm{C} 1 s$ and $\mathrm{N} 1 s$ spectra to obtain quantitative results, because of the large number of overlapping peaks.

The lattice image of AlN-SiC alloy crystal (which was grown on $8^{\circ}$ off-axis $6 \mathrm{H}-\mathrm{SiC}$ substrate at $1985^{\circ} \mathrm{C}$ for $24 \mathrm{~h}$ ) at $\langle 11 \overline{2} 0\rangle$ projection and its corresponding diffraction pattern shown in Figure 8 confirms that it was a wurtzite structured crystal. EDX measurements indicate that the crystals were really alloys of AlN and $\mathrm{SiC}$, with a rough estimate of the $\mathrm{SiC}$ composition of several tens of percentage.

The origin and paths of defects were examined by TEM. Figure 9 demonstrates the dislocation density in the initial growth was on the order of $10^{10} \mathrm{~cm}^{-2}$. The threading dislocations bent over as the alloy layer became thicker, and propagated horizontally (as shown by Figure 10). The defect density was reduced significantly at the surface region to less than $10^{8} \mathrm{~cm}^{-2}$. In a second sample repeated at the same growth condition, the dislocations propagated in a zigzag manner from the beginning. The dislocation density at the alloy surface was less than $10^{6} \mathrm{~cm}^{-2}$, which exceeded the examination limit of cross-section sampling. It was 3 orders of mag- 
nitude lower than the dislocation density at the early stage of growth of $10^{9} \mathrm{~cm}^{-2}$.

The composition of the alloy crystal should depend on the vapor phase composition, and the diffusion rate of each vapor species. Diffusion rates are generally inversely proportional to the molecular weight of species involved. Therefore, $\mathrm{Al}$ and $\mathrm{Si}$ should diffuse at rates with the same order of magnitude, with the diffusion rates of $\mathrm{Si}_{2} \mathrm{C}, \mathrm{Si}_{2} \mathrm{~N}$ and $\mathrm{SiC}_{2}$ much lower. Consequently, the overall diffusion rate of Al-containing species (only $\mathrm{Al}$ ) should be higher than that of Si-containing species $\left(\mathrm{Si}, \mathrm{Si}_{2} \mathrm{C}, \mathrm{Si}_{2} \mathrm{~N}\right.$, and $\left.\mathrm{SiC}_{2}\right)$. An approximately uniform composition was achieved from the interface to the crystal surface, as confirmed by both XPS and EPMA. When the source composition AlN:SiC was 3:1 (growth was repeated for three times under the same growth conditions of $1850{ }^{\circ} \mathrm{C}$ and $24 \mathrm{~h}$ ), XPS measurements demonstrated non-stoichiometric ratios of $\mathrm{Al}: \mathrm{N}$ and $\mathrm{Si}: \mathrm{C}$. The $\mathrm{N}$ concentration was always slightly higher than the $\mathrm{Al}$ concentration (5-15\%). The ratio of $\mathrm{Al}: \mathrm{Si}$ was higher than 3 (3.6-4.4), comparable to 4.0 in the gas phase as predicted by JANAF calculation in Figure 1. In comparison, the $\mathrm{N}$ concentration measured by EPMA was also higher than $\mathrm{Al}$ (10-14\%), however, the ratio of $\mathrm{Al}: \mathrm{Si}$ was lower than 3 (1.8-2.4), independent of the wide range of growth temperature from $1860{ }^{\circ} \mathrm{C}$ to $1990{ }^{\circ} \mathrm{C}$. The $\mathrm{Si}$ concentration by EPMA differed significantly from that by XPS, with EPMA giving a much higher Si content. When the mole ratio of $\mathrm{Al}: \mathrm{Si}$ in the source material was 5:1 and 2:1, the ratio of $\mathrm{Al}: \mathrm{Si}$ in the alloy crystals changed with the growth temperature, and it was different from the original composition, which agreed well with the results calculated by JANAF data.

\section{Conclusions}

AlN-SiC alloy crystals were grown on as-received $4 \mathrm{H}-$ and $6 \mathrm{H}-\mathrm{SiC}$ substrates with different misorientation angles by sublimation-recondensation in a resistivelyheated graphite furnace. On-axis $\mathrm{SiC}$ substrate was proven not suitable for the seeded growth of AlN-SiC alloy crystals. Different polytypes $(6 \mathrm{H}$ or $4 \mathrm{H})$ and miscut $\left(8^{\circ}\right.$ or $\left.3.68^{\circ}\right)$ had negligible effect on the crystal morphology. The AlN-SiC alloy crystal had non-stoichiometric ratios of $\mathrm{Al}: \mathrm{N}$ and $\mathrm{Si}: \mathrm{C}$. Homogeneous wurtzite structured compounds of AlN and $\mathrm{SiC}$ were obtained, with a decreasing dislocation density away from the crystal/substrate interface. The mole ratio of $\mathrm{Al}$ to $\mathrm{Si}$ in the final alloy crystals changed with the growth temperature, and differed from the original source composition, which was consistent with the thermodynamic predictions.

\section{ACKNOWLEDGMENTS}

We are thankful to the research sponsored in part by the Assistant Secretary for Energy Efficiency and Renewable Energy, Office of FreedomCar and Vehicle Technologies, as part of the High Temperature Materials Laboratory User Program, Oak Ridge National Laboratory, managed by UTBattelle, LLC, for the U.S. Department of Energy under contract number DE-AC05-00OR22725. The XPS work was performed at the EMSL, a national scientific user facility sponsored by DOE's Office of Biological and Environmental Research and located at Pacific Northwest National Laboratory, operated for DOE by Battelle. Support from the National Science Foundation, grant number DMR-0408874, is gratefully appreciated.

\section{REFERENCES}

[1] Y. Shi, B. Liu, Lianghong Liu, J.H. Edgar, E.A. Payzant, J. M. Hayes, Martin Kuball, MRS Internet J. Nitride Semicond. Res. 6, 5 (2001).

[2] C.E. Hunter, "Growth of bulk single crystals of aluminum nitride:silicon carbide alloys", CODEN: USXXAM US 6086672 A 20000711 (2000). "The author describes a patented method to grow bulk single crystalline AIN:SiC alloys with a fast growth rate."

[3] C.E. Hunter, "Production of bulk single crystals of aluminum nitride, silicon carbide and aluminum nitride:silicon carbide alloy", PCT Int. Appl. CODEN: PIXXD2 WO 2000022203 A2 20000420 (2000). "The author reports a patented sublimation method to grow bulk single crystalline AlN, SiC, and AlN:SiC alloys."

[4] I. B. Cutler, P. D. Miller, W. Rafaniello, H. K. Park, D. P. Thomson, K. H. Jack, Nature 275, 434 (1978).

[5] V. A. Dmitriev, Springer Proc. Phys. 56, 3 (1992).

[6] Sh. A. Nurmagomedov, A. N. Pikhtin, V. N. Razbegaev, G. K. Safaraliev, Yu. M. Tairov, V. F. Tsvetkov, Fiz. Tech. Polupr. 23, 162 (1989).

[7] R. S. Kern, S. Tanaka, R. F. Davis, Inst. Phys. Conf. Ser. 137, 389 (1994).

[8] K. Wongchotigul, M. G. Spencer, N. Chen, B. D. Prasad, Mater. Lett. 21, 381 (1994).

[9] G. K. Safaraliev, Yu. M. Tairov, V. F. Tsvetkov, Sov. Phys. Semicond. 25, 865 (1991).

[10] Z. Gu, J. H. Edgar, E. A. Payzant, H. M. Meyer, L. R. Walker, A. Sarua, M. Kuball, Mater. Res. Soc. Symp. Proc. 831, E3.1.1 (2005).

[11] V. Dmitriev, A. Cherenkov, J. Cryst. Growth 128, 343 (1993).

[12] I. Jenkins, K. G. Irvine, M. G. Spencer, V. Dmitriev, N. Chen, J. Cryst. Growth 128, 375 (1993).

[13] A. Avramescu, H. Hirayama, Y. Aoyagi, S. Tanaka, J. Cryst. Growth 234, 435 (2002).

[14] R. Roucka, J. Tolle, D. J. Smith, P. Crozier, I. S. T. Tsong, J. Kouvetakis, Appl. Phys. Lett. 79, 2880 (2001).

[15] R. A. Yankov, W. Fukarek, M. Voelskow, J. Pezoldt, W. Skorupa, Mater. Sci. Forum 264-268, 753 (1998). 
[16] X. Peng, L. Song, J. Le, X. Hu, J. Vac. Sci. Technol. B 20, 159 (2002).

\section{FIGURES}

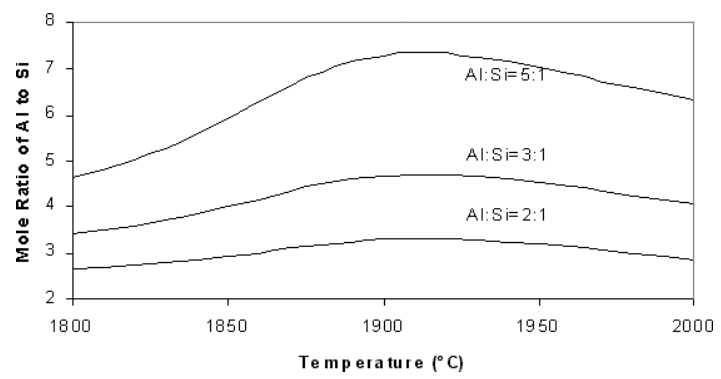

Figure 1. Calculated mole ratio of $\mathrm{Al}: \mathrm{Si}$ in the gas phase during the sublimation growth of AlN-SiC alloy crystals when the mole ratio of $\mathrm{Al}: \mathrm{Si}$ in the source material is $2: 1,3: 1$ and 5:1.

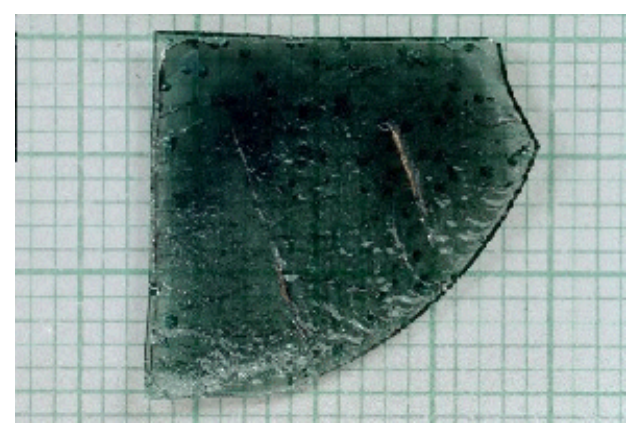

Figure 2a. Optical micrograph of AlN-SiC alloy crystal grown on $8^{\circ}$ off-axis $6 \mathrm{H}$-SiC substrate at $1860{ }^{\circ} \mathrm{C}$ for $24 \mathrm{~h}$ (the smallest grid size is $5 \mathrm{~mm}$ ).

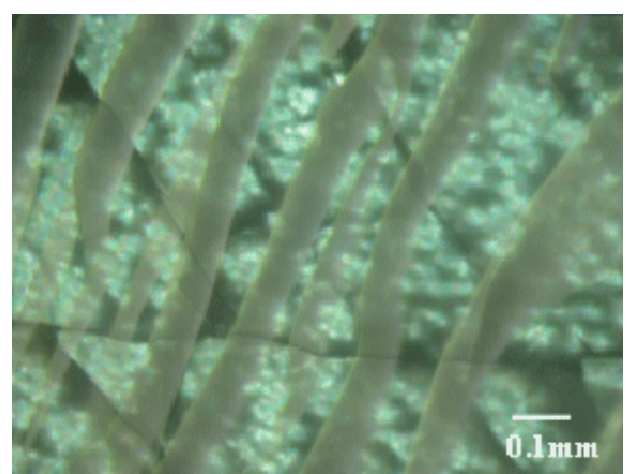

Figure 2b. Optical micrograph of AlN-SiC alloy crystal grown on $8^{\circ}$ off-axis $6 \mathrm{H}-\mathrm{SiC}$ substrate at $1860{ }^{\circ} \mathrm{C}$ for $24 \mathrm{~h}$ (magnification: 200X).

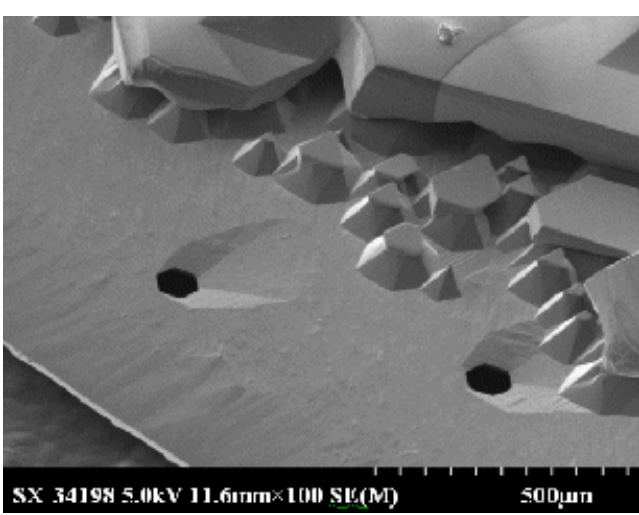

Figure 3a. SEM of AlN-SiC alloy crystal grown on $8^{\circ}$ off-axis $6 \mathrm{H}-\mathrm{SiC}$ substrate at $1860^{\circ} \mathrm{C}$ for $20 \mathrm{~h}$.

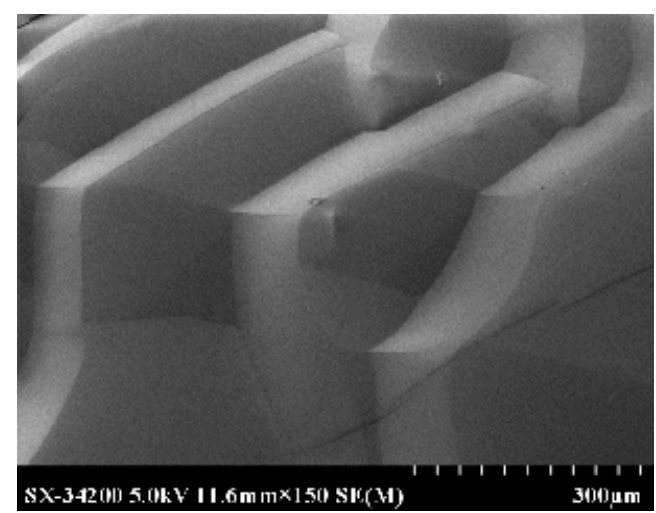

Figure $3 \mathrm{~b}$. SEM of AlN-SiC alloy crystal grown on $8^{\circ}$ off-axis $6 \mathrm{H}-\mathrm{SiC}$ substrate at $1860^{\circ} \mathrm{C}$ for $20 \mathrm{~h}$.

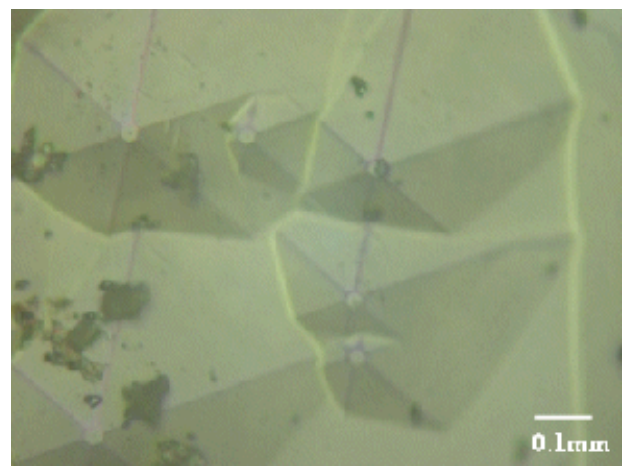

Figure 4. Optical micrograph of AlN-SiC alloy crystal grown on on-axis $6 \mathrm{H}-\mathrm{SiC}$ substrate at $1850^{\circ} \mathrm{C}$ for $24 \mathrm{~h}$ (magnification: 200X). 


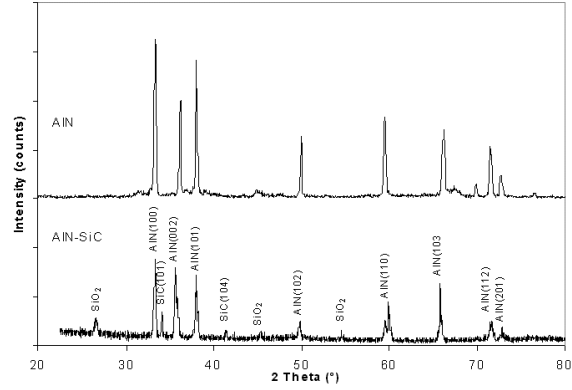

Фirope 5. $\theta-2 \theta$ XRD patterns for $\mathrm{AlN}-\mathrm{SiC}$ alloy crystal grown on $8^{\circ}$ off-axis $6 \mathrm{H}-\mathrm{SiC}$ substrate at $1985^{\circ} \mathrm{C}$ for $24 \mathrm{~h}$.

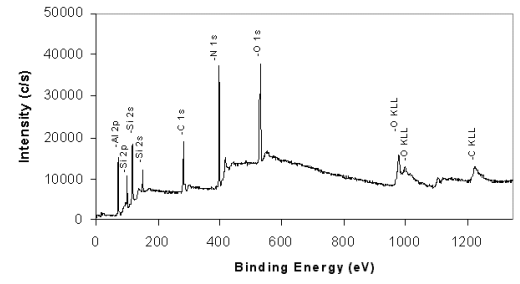

Figure 6. XPS spectra for AlN-SiC alloy crystal grown on $8^{\circ}$ off-axis $6 \mathrm{H}-\mathrm{SiC}$ substrate at $1865^{\circ} \mathrm{C}$ for $24 \mathrm{~h}$.

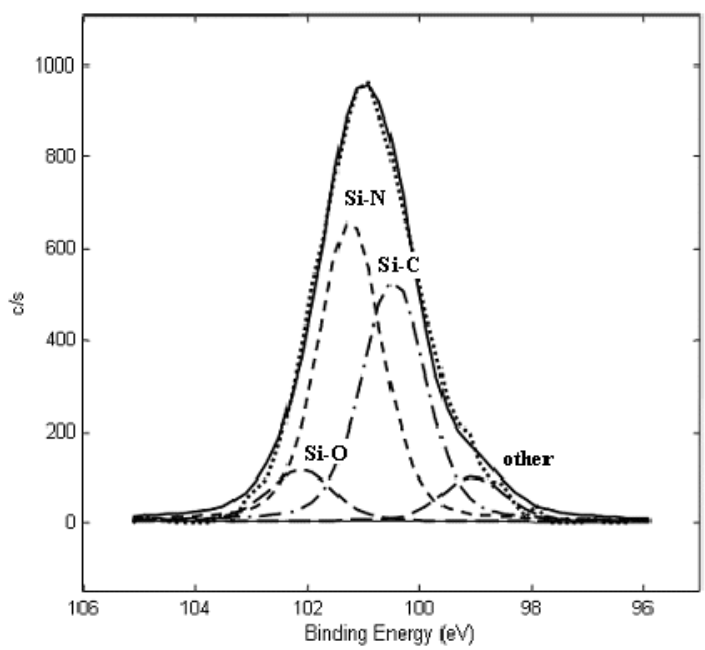

Figure 7. High resolution photoemission spectra of the Si $2 p$ region for AlN-SiC alloy crystal grown on $8^{\circ}$ off-axis $6 \mathrm{H}-\mathrm{SiC}$ substrate at $1850{ }^{\circ} \mathrm{C}$ for $24 \mathrm{~h}$ (with the background subtracted).

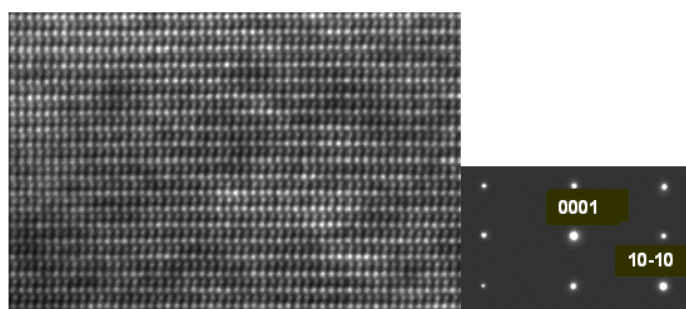

Figure 8. Lattice image and its corresponding diffraction pattern of AlN-SiC alloy at $\langle 11 \overline{2} 0\rangle$ projection grown on $8^{\circ}$ offaxis $6 \mathrm{H}-\mathrm{SiC}$ substrate at $1985^{\circ} \mathrm{C}$ for $24 \mathrm{~h}$.

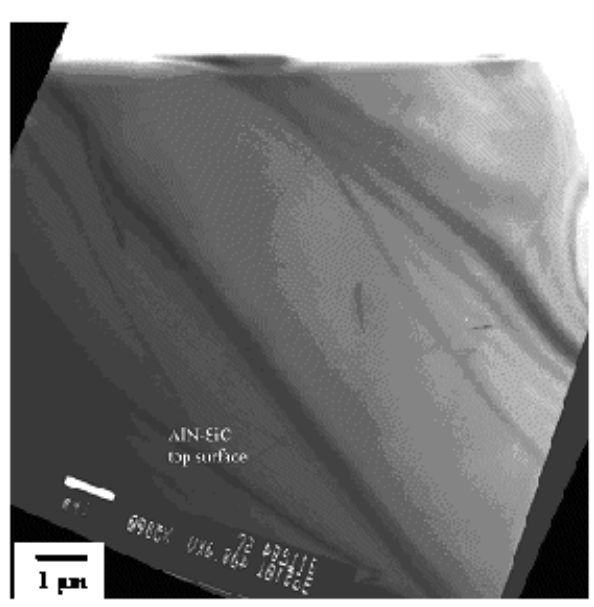

Figure 9a. TEM image for AlN-SiC alloy crystal grown on $8^{\circ}$ off-axis $6 \mathrm{H}-\mathrm{SiC}$ substrate at $1985{ }^{\circ} \mathrm{C}$ for $24 \mathrm{~h}$ (AlN-SiC alloy crystal surface).

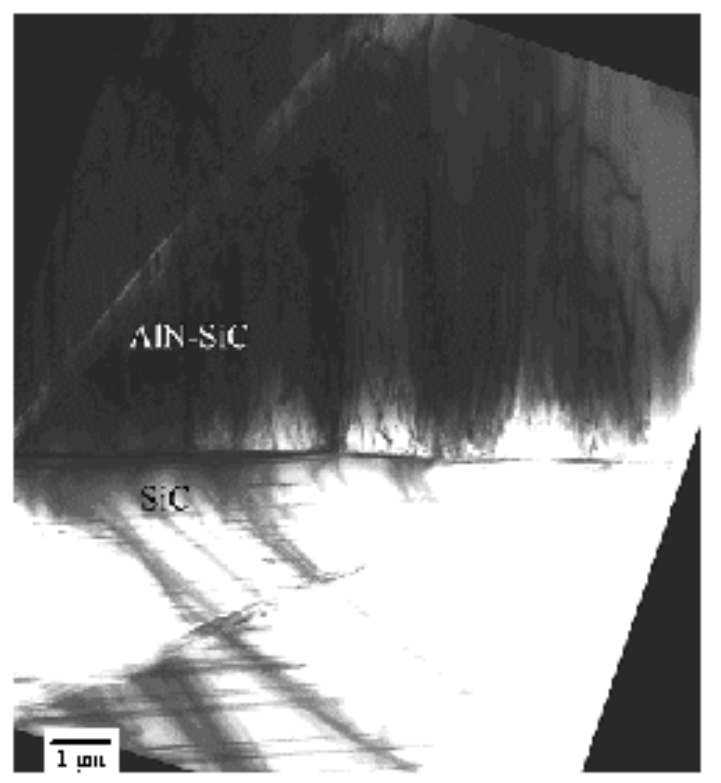

Figure 9b. TEM image for AlN-SiC alloy crystal grown on $8^{\circ}$ off-axis $6 \mathrm{H}-\mathrm{SiC}$ substrate at $1985^{\circ} \mathrm{C}$ for $24 \mathrm{~h}$ (cross-sectional image). 


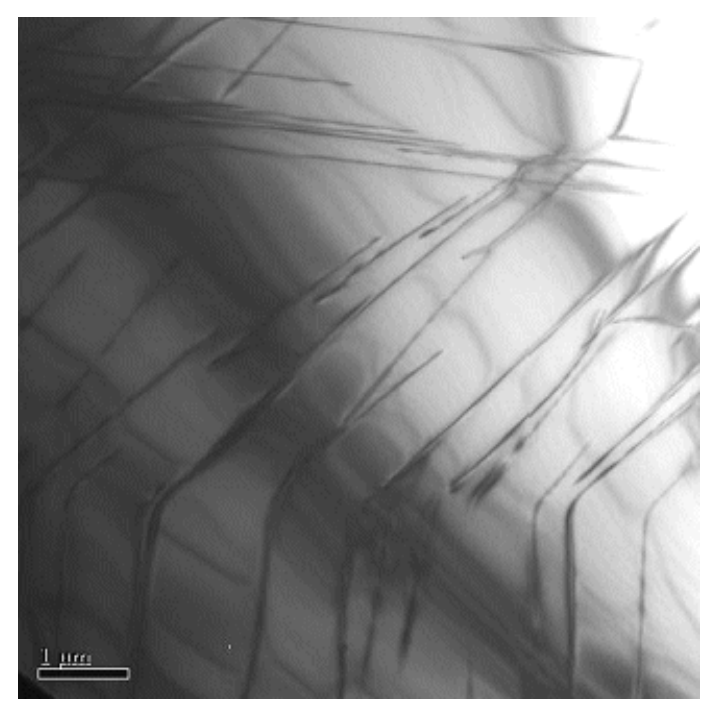

\section{TABLES}

Table 1. Binding energies of fitted features of $\mathrm{Si} 2 p$ XPS peaks of two AlN-SiC alloy crystals grown on $8^{\circ}$ off-axis $6 \mathrm{H}-\mathrm{SiC}$ substrate at different temperatures.

\begin{tabular}{|l|l|l|l|l|}
\hline Sample & Element & Bond & $\begin{array}{l}\text { Binding } \\
\text { energy } \\
\text { (eV }\end{array}$ & $\begin{array}{l}\text { Relative } \\
\text { intensity }\end{array}$ \\
\hline $1850^{\circ} \mathrm{C} / 24 \mathrm{~h}$ & $\mathrm{Si}$ & $\mathrm{Si}-\mathrm{C}$ & 100.48 & 0.3489 \\
\hline & & Si-N & 101.25 & 0.4841 \\
\hline & & Si-O & 102.13 & 0.0991 \\
\hline & & other & 99.07 & 0.0679 \\
\hline & 0 & & 531.7 & \\
\hline $1865^{\circ} \mathrm{C} / 24 \mathrm{~h}$ & $\mathrm{Si}$ & Si-C & 100.48 & 0.2646 \\
\hline & & Si-N & 101.25 & 0.5275 \\
\hline & & Si-O & 102.13 & 0.1542 \\
\hline & & other & 99.07 & 0.0537 \\
\hline & 0 & & 531.7 & \\
\hline & & & & \\
\hline
\end{tabular}

Figure 10. TEM image for AlN-SiC alloy crystal grown on $8^{\circ}$ off-axis $6 \mathrm{H}-\mathrm{SiC}$ substrate at $1985{ }^{\circ} \mathrm{C}$ for $24 \mathrm{~h}$, showing the bending of the threading dislocations at specific positions and propagating horizontally. 